\title{
La Concretización de la Justicia Ambiental: Caso del Rio Santiago en los Municipios de El Salto y Juanacatlán ${ }^{1}$
}

\section{The Realization of Environmental Justice: Case of the Santiago River in the Municipalities of El Salto and Juanacatlán.}

DOI: 10.32870/sincronia.axxv.n80.30b21

\author{
Elizabeth Leticia Souza Mosqueda \\ Departamento de Derecho Privado. Universidad de Guadalajara. (MÉXICO) \\ CE: ceding@hotmail.com / ID ORCID: 0000-0003-4775-9025 \\ Martín Moreno Reynaga \\ Posgrado en Derecho. Universidad de Guadalajara (MÉXICO) \\ CE: a.j.moreno.r@hotmail.com / ID ORCID: 0000-0002-9548-3273 \\ Angelica Jesús Ceceña Altamirano \\ Derecho Público. Universidad de Guadalajara (México) \\ CE: lexangelica@gmail.com / ID ORCID: 0000-0003-3175-5302 \\ Cynthia Ramírez Ramírez \\ CE: lepg.cynthia.rmz@hotmail.com / ID ORCID: 0000-0001-5175-5970 \\ Daland Alexis Franco Vázquez \\ Abogado. Universidad de Guadalajara (MÉXICO). \\ CE: daland.franco@gmail.com / ID ORCID: 0000-0003-0715-9797
}

Esta obra está bajo una Licencia Creative Commons Atribución-NoComercial 4.0 Internacional

Recibido: 31/03/2021

Revisado: 30/04/2021

Aprobado: $11 / 05 / 2021$

\footnotetext{
${ }^{1}$ El presente artículo es el resultado del proyecto de investigación titulado: "La Justicia Ambiental: caso del Rio Santiago en los Municipios El Salto y Juanacatlán". Es producto del trabajo colegiado de investigación que sintetizan la experiencia de las acciones en vinculación de los cuerpos académicos UDG-CA-267 y UDGCA-785.
} 


\section{RESUMEN}

El presente trabajo de investigación desarrolla el problema de la aplicación del marco jurídico del derecho al agua para su protección y reparación así como al medio ambiente ya que este guarda una estrecha relación con el primer derecho mencionado, cuando existe una afectación. Para ello estudiamos el caso del Rio Santiago, uno de los cuerpos de agua más importantes de México y con mayor longitud, por esta razón, cuando se hable de Río Santiago nos referiremos al cuerpo de agua ubicado en los municipios de Juanacatlán y el Salto del Estado de Jalisco, el cual, desde hace tiempo fue contaminado al verter diversos tipos de sustancias, sin que a la fecha se tomen medidas para disminuir dicha actividad. Esto se realiza con el estudio del marco jurídico nacional e internacional en la materia, para después desarrollar las circunstancias en que provocaron el daño al Río, y como estas, incentivaron que las diversas autoridades emitieran resoluciones intentando reparar el daño. A pesar de existir dichas determinaciones, no son suficientes para la protección de este derecho, por lo que al final proponemos la creación de un tribunal de justicia ambiental que sea capaz de resolver este tipo de problemas.

Palabras claves: Rio Santiago, derecho al agua, justicia ambiental.

\section{ABASTRACT}

This research work develops the problem of the application of the legal framework of the right to water for its protection and reparation as well as to the environment, since this is closely related to the first mentioned right, when there is an affectation. For this, we study the case of the Santiago River, one of the most important bodies of water in Mexico and with the longest length.For this reason, when we talk about the Santiago River we will refer to the body of water located in the municipalities of Juanacatlán and Salto del State of Jalisco, which, for a long time, was contaminated by dumping various types of substances, without measures being taken to reduce said activity to date. This is done with the study of the national and international legal framework on the matter, to later develop the circumstances in which they caused the damage to the River, and like these, they encouraged the various authorities to issue resolutions trying to repair the damage. Despite the existence of such determinations, they are not sufficient for the protection of this right, so in the end we propose the creation of an environmental court that is capable of solving these types of problems. 
Keywords: Rio Santiago, right to water, environmental justice.Keywords: Rio Santiago, right to water, environmental justice.

\section{Introducción}

El deterioro al medio ambiente es una constante que cada vez se agrava de mayor manera en el entorno mundial, el cual afecta al Estado de Jalisco debido a que se encuentra uno de los cuerpos hídricos más importantes del país, que resulta ser uno de los más contaminados por sustancias toxicas por metales pesados y compuestos sintéticos de alta volatilidad en las últimas décadas. Existen varios actores en esta problemática: las leyes, la economía, empresas y la sociedad en general; ello ha lleva a la búsqueda de una solución, focalizando una zona de alto riesgo ubicada en los municipios del Salto y Juanacatlán. Esta circunstancia condujo a la emisión de una recomendación por parte de la Comisión Estatal de Derechos Humanos la cual no solucionó el problema. Esto genera como objetivo general en el presente artículo, demostrar la ineficacia de la legislación vigente, así como de los organismos no vinculantes y la evaluación de sus documentos emitidos, por la falta de un tribunal encargado de impartir justicia ambiental. En lo relativo a los objetivos específicos es menester establecer la necesidad de la creación de una instancia jurisdiccional de pleno derecho con capacidad coercitiva, sumaría y expedita para la importancia de los asuntos que se someterán a su competencia, así como de la evolución el desarrollo de sus procesos. La necesidad de sentencias que puedan proteger y reparar cualquier violación de derecho al agua y al saneamiento vulnerando a su vez el medio ambiente, para prevenir más casos parecidos al observable en El Santo Y Juanacatlán.

\section{Estudio sobre el marco jurídico nacional del derecho humano al agua.}

En los últimos años, el medio ambiente y el agua adquirieron gran importancia en las actividades cognoscibles, incluidas el derecho. Ello provocó que el Estado Mexicano tomara conciencia de la necesidad de proteger dichos bienes, mediante una serie de modificaciones en los sistemas jurídicos para el reconocimiento derecho al agua como derecho humano, imponiendo las 
obligaciones de promoverlo, respetarlo, protegerlo y garantizarlo, cargo del Estado para su preservación e imponiendo el deber de comprender el nuevo paradigma.

Esto fue parte del proceso de la materialización de nuestra carta magna, porque a partir del reconocimiento de los derechos humanos se renovó la forma en que el Estado actúa, y cambió la forma en que las autoridades deben conducirse en atención a los nuevos derechos que adquirieron para satisfacer el disfrute de estos dentro de las diversas facetas de las personas, tanto individual como colectivamente.

Este derecho fue reconocido en el artículo $4^{\circ}$ de la Constitución Política de los Estados Unidos Mexicanos (2021), precisando que las personas que habiten o transiten por el país gozarán del derecho al acceso del agua para si disposición y saneamiento. En el proceso de reforma constitucional, estos principios dejaron de ser un conjunto de buenas intenciones que establecían una finalidad a realizar por el Estado, sino que se convirtieron en derechos exigibles de los que se deben crear condiciones para su satisfacción progresiva.

De la misma manera, al considerar nuestra constitución que los tratados de derechos humanos tienen la misma jerarquía que la carta magna (Constitución Política de los Estados Unidos Mexicanos, 2021, art. $1^{\circ}$ ), se reconoció su protección por la Convención Americana de Derechos Humanos (1969) en su artículo 26, el cual establece el mandato hacia los Estados de lograr la satisfacción de los derechos sociales -grupo al que pertenece el derecho al agua- de manera progresiva. Por otro lado, ante la necesidad de un marco jurídico internacional que regulara de manera amplia estos derechos, fue elaborado el Protocolo Adicional a la Convención Americana sobre Derechos Humanos en Materia de Derechos Económicos, Sociales y Culturales "Protocolo de San Salvador" (1999), donde se protege este derecho en el artículo 11 mediante la tutela al derecho al medio ambiente sano, reforzando el deber del estado de implementar mecanismos con los cuales este derecho se satisfaga de manera gradual, pero que en cada una, dicho acceso mejore.

Para desarrollarlos, es importante comprender la relación que tienen con el capítulo económico del mismo documento, puesto que en él se establece el deber a cargo del Estado sobre la planeación, la cual, dentro de los artículos 25 y 26 (Constitución Política de los Estados Unidos 
Mexicanos, 2021) impone una fuerte carga al desarrollo bajo el principio de sustentabilidad, señalando el deber realizar el desarrollo de manera racional y planificada, garantizando que los recursos naturales -entre ellos el agua- puedan ser utilizados por las personas para satisfacer sus necesidad y que sean suficientes para las futuras generaciones.

Ante el nuevo paradigma de la constitución, resulta insuficiente el simple reconocimiento del derecho al agua para su protección, por lo que se hizo menester desarrollar el contenido de cada derecho en una ley que sirva como garantía para su satisfacción. Esto provocó que la Ley General del Equilibrio Ecológico y la Protección al Ambiente (2018) fuera entendida como el mecanismo garantista a partir de su última reforma, al señalarse que reglamenta aquellas disposiciones relacionadas con el medio ambiente. Por ello, su finalidad consiste en el desarrollo sustentable del medio ambiente, así como la preservación y restauración del equilibrio ecológico. Ante ello, los objetivos de esta ley son:

1. Garantizar el derecho de toda persona a vivir en un medio ambiente sano;

2. Definir los conceptos de política ambiental;

3. Establecer las bases para el aprovechamiento adecuado de los recursos naturales;

4. Prevenir y controlar la contaminación del agua, aire y suelo;

5. Desarrollar mecanismos de colaboración entre gobierno, sector privado y social, así como demás entes con interés en materia ambiental;

6. Establecer aquellas que permitan desarrollar a las instituciones, autoridades y demás sectores relacionados, crear las estructuras de organización para la defensa de los derechos y cumplimiento de obligaciones previstas en esta norma (art. $1^{\circ}$ ).

Con ello comienza el desarrollo del contenido sustantivo de nuestro documento fundamental, esclareciendo las diversas obligaciones que debe cumplir el Estado Mexicano para la mayor protección del derecho, vinculando su contenido a todos los órdenes de gobierno debido a su generalidad, por lo que cada autoridad, en el ámbito de sus competencias, debe cumplir con lo establecido en ella ante la generalidad que irradia el ámbito de sus decisiones. 
Sin embargo, esto representa un desafío para el Estado de Jalisco, en especial porque modifica su forma de actuar, pasando de un ente pasivo a uno activo constreñido a tomar aquellas medidas necesarias para su adecuado cumplimiento, considerando que forman parte de la planeación.

Para facilitad este objetivo, la ley comienza a delimitar sus obligaciones, señalando que una medida especifica es la prevención y contaminación del agua. Por ello, la Ley General del Equilibrio Ecológico y la Protección al Ambiente (2018) estipula cinco criterios que permiten al Estado el cumplimiento de este objetivo, los cuales son:

1. La protección de los ecosistemas del país;

2. La prevención de la contaminación mediante la intervención del Estado-Sociedad en cualquiera de las formas y lugares en que se encuentre el agua;

3. Diseñar actividades productivas sustentables;

4. Elaborar programas para el tratamiento de aguas residuales en áreas urbanas y

5. Diseñar estrategias que permitan la participación constante de la sociedad (art. 22 BIS).

Ante ello, el legislador tomó dichos principios para desarrollar el sistema en el que las autoridades observaran para la ministración de agua, elaborando las bases de un sistema de administración coordinado entre los tres niveles de gobierno. Por ello, el artículo 117 de la Ley General del Equilibrio Ecológico y la Protección al Ambiente (2018) señala que la administración está a cargo de la federación, teniendo una participación activa las entidades federativas y los municipios, exhortando una aplicación directa de las legislaciones estatales. Esta administración refuerza el tratamiento de aguas residuales producidas por el sistema de drenaje y alcantarillado, delegando la responsabilidad de vigilar que las descargas se hagan con los controles adecuados. Por otro lado, establece sanciones en caso de que lo anterior no se realice conforme a ley. Por último, impone el deber de realizar un registro de las éstas.

En ese sentido la misma normativa precisa que la federación, las Entidades Federativas, los Municipios y la Ciudad de México podrán trabajar en coordinación para poder preservar y restaurar 
el equilibrio ecológico y los cuerpos acuíferos en el país, a partir de actividades que bajo su respectiva jurisdicción tendrán que implementar, pudiendo aplicar otros ordenamientos para la política ambiental nacional y participación de la sociedad en la materia.

Tal es el caso de la Ley de Aguas Nacionales (2020), la cual, de conformidad a su artículo $1^{\circ}$, es otra ley que garantiza este derecho humano. El objetivo de este ordenamiento jurídico es regular la explotación, uso o aprovechamientos de las aguas nacionales, su control y distribución, así como la preservación de la cantidad y calidad para lograr su desarrollo integral sustentable. Esta precisa que cualquier tipo de recurso hídrico que este en subsuelo, superficie y los mares, serán regulados por esta ley, también precisa en el artículo $2^{\circ}$ que buscará preservar en todo momento el buen estado de las mismas.

Entre las diversas medidas de cuidado y preservación de los recursos naturales hídricos, para el fomento de un desarrollo sustentable, el artículo $1^{\circ}$ de la Ley de Aguas Nacionales (2020) reglamenta el uso, explotación, cuidado y mantenimiento de los cuerpos hídricos a cargo de los asignatarios y concesionarios. De la misma manera, el artículo 17 de esa misma ley precisa no es necesario tener el nombramiento por alguna autoridad de asignatario o concesionario, sino que cualquier persona puede hacer uso de los recursos hídricos en ríos, causes o cuenca hidrológica, siempre y cuando no afecten las corrientes naturales o generen una contaminación dentro de los mismos bajo ciertas condiciones, como una forma de proteger el derecho al acceso al agua, estableciendo condiciones que permitan su preservación.

Es por ello que no distingue entre personas físicas o jurídicas; sector público, privado o social para ejercer dicho derecho. La ley prevé la participación de cualquiera en los comités y consejos consultivos del agua; esta procura establecer un equipo que ese íntimamente ligado con el recurso natural, permitiendo participar a todos aquellos que tengan conocimientos relacionados con el manejo y preservación del agua en diversas materias.

Por otro lado, como una ley cuya finalidad es el desarrollo y protección de este derecho humano, se establecieron en el artículo 119 de la Ley de Aguas Nacionales en su Título Décimo (2020) las sanciones que la autoridad correspondiente impondrá a quienes cometan un acto 
considerado perjudicial para el objeto de esta ley. En total, existen 24 sanciones, de las que se resaltan las siguientes:

1. Descargar en forma permanente, intermitente o fortuita aguas residuales en contravención a lo dispuesto en la presente Ley en cuerpos receptores que sean bienes nacionales, incluyendo aguas marinas, así como cuando se infiltren en terrenos que sean bienes nacionales o en otros terrenos cuando puedan contaminar el subsuelo o el acuífero.

2. Omitir la implementación de instalaciones que prevengan la afectación al medio ambiente o los derechos de las personas

3. No instalar, no conservar, no reparar o no sustituir, los dispositivos necesarios para el registro o medición de la cantidad y calidad de las aguas, en los términos que establece esta Ley, sus reglamentos y demás disposiciones aplicables, o modificar o alterar las instalaciones y equipos para medir los volúmenes de agua explotados, usados o aprovechados, sin permiso correspondiente, incluyendo aquellos que en ejercicio de sus facultades hubiere instalado "la Autoridad del Agua".

4. Explotar, usar o aprovechar aguas nacionales sin el título respectivo, cuando así se requiere en los términos de la presente Ley.

5. Arrojar o depositar cualquier contaminante, en contravención a las disposiciones legales, en cualquier tipo de cuerpo acuífero;

6. No cumplir con las obligaciones consignadas en los títulos de concesión, asignación o permiso de descarga.

7. Ocasionar daños ambientales considerables o que generen desequilibrios, en materia de recursos hídricos de conformidad con las disposiciones en la materia.

De esta manera, todo tipo de descargas residuales, sean en cuencas, ríos, aguas marinas, corrientes de agua entre otros más vertederos hídricos serán sancionados cuando transgredan las Normas Oficiales Mexicanas o las condiciones de descargas para origen industrial, municipal, agropecuarias o también las que contengan plaguicidas, sustancias toxicas, residuos y deshechos.

En aquellas zonas que se encuentren en peligro y deterioro ecológico por contaminación u otra forma en que un agente perturbador actué, o en caso de que las zonas estén en riesgo porque 
el peligro sea inminente ante un proceso acelerado de degradación los recuro naturales, ocasionando que las afectaciones provoquen un impacto ambiental irreversible, la federación deberá declarar zona de restauración ecológica con estudios previos que lo justifiquen.

Ahora bien, es importante señalar que el marco jurídico para la protección del derecho al medio ambiente y al agua se ve afectado en la cuenca del Río Santiago, puesto que el Estado otorga primacía a la actividad económica de los habitantes de la zona, lo cual ocasiona el deterioro ecológico por el abuso del principal recuso natural que se utiliza en cualquier actividad del hombre: el agua. Primeramente, esto se debe a que permite el abastecimiento se vea afectado para favorecer a las industrias en sus actividades; el segundo problema radica en la contaminación ocasionada al cuerpo acuífero por los desechos industriales, ya sea de manera directa o indirecta, porque las aguas al ser contaminadas y seguir su cauce natural, propagan estas a aquellos cuerpos acuíferos con los que conecta.

En ese sentido, debemos considerar que, los planes de desarrollo no están homologados con los principios señalados, además de existir una parsimonia en la aplicación de sanciones, comienzan los problemas en el cumplimiento de respetar, proteger y garantizar este derecho, ocasionando lesiones a la esfera jurídica de las personas de manera sistemática, puesto que la transgresión a este derecho ocasiona la violación a otros, por las omisiones del estado al no realizar las acciones suficientes para protegerlo.

\section{Estudio sobre el marco jurídico internacional del derecho humano al agua.}

A pesar de existir un marco jurídico amplio para la protección del derecho al agua y sus vertientes en el derecho nacional, existe otro igual de amplio en el derecho internacional, mismo que lo protege considerándolo un elemento importante del medio ambiente, y que fomentó un amplio debate sobre su necesidad. Para ello, los principios del derecho ambiental protegen de manera amplia el derecho al agua, señalando el deber del Estado Mexicano de desarrollar el contenido de cada uno. Por ello, es importante comprender cuales son los principales documentos 
internacionales que protegen este derecho y su desarrollo, mismos que crearon una guía internacional de protección.

Iniciaremos con la modificación al estudio del derecho ambiental del día 16 de junio de 1972, en ocasión a la proclamación de la Declaración de Estocolmo sobre el Medio Ambiente Humano. Este documento establece los principios generales del derecho internacional para el medio ambiente, los cuales fueron aceptados por los miembros de la Organización de las Naciones Unidas, mismos que deben ser respetados y observados como marco base por cada uno de los países firmantes.

En este documento se establecieron de manera general principios con redacción propia y objetivos únicos, declarando que el ser humano es quien transforma en el medio ambiente como consecuencia de las actividades que realiza, modificando el anterior paradigma donde se disponía que la naturaleza era quien moldeaba la moral y el desarrollo intelectual del hombre.

De lo anterior iniciaron cambios para incluir el derecho ambiental en los diversos jurídicos entendiendo el lugar que ahora tenía en medio ambiente, por lo cual, con base en Eschenhagen (2006) podemos enumerar dichos elementos de la siguiente manera:

1. Se concientizo y acordó por primera vez que los recursos naturales son limitados;

2. Se estableció el día mundial de la tierra o medio ambiente;

3. Se creó el Programa de las Naciones Unidas para el Medio Ambiente;

4. Se preciso que uno de los problemas ambientales es la preminencia de la política económica sin límites legales;

5. Se señala la gran relevancia de la contaminación y sus efectos negativos en descargas de residuos tóxicos en el medio ambiente;

6. Se establece planificación futura para uso, goce y disfrute de los recursos naturales a las nuevas generaciones;

7. Se impulsa la participación ciudadana por medio de la educación como medida de prevención y control ecológico;

8. Se propone distribuir la responsabilidad ambiental en coordinación para actividades en conjunto (pp. 41 - 45). 
En ese sentido, es importante considerar que en la Declaración de Estocolmo (1972) se señaló que el espacio natural y artificial es ineludible y manteniendo una interacción constante por la actividad económica, por lo que mantener un adecuado control de ambos es prioritario para el desarrollo, puesto que uno depende del otro, ante el desarrollo indispensable para poder ofrecer bienestar y calidad de vida (proclamación I).

A pesar de que ya han pasado varias décadas desde la declaración de Estocolmo, sobresale el hecho de que, no obstante ser el primer documento internacional de derecho ambiental, brinda principios suficientes para la compresión y mejoramiento del derecho ambiental. Ahora bien, desde los inicios de las reuniones se establecieron objetivos específicos, pero los problemas inertes a la humanidad incitan la evolución científica de manera rápida, lo que impacta las practicas económicas y ello, que se acelere el cambio climático.

Esto ocasiono que continuaran los trabajos internacionales en esta materia, en un esfuerzo de constante adaptación y actualización, provocando que en junio de 1992 en la ciudad de Rio de Janeiro, Brasil, se elaborara un documento donde se estableció el objetivo principal de cooperación entre naciones, entes privados y sociedad civil. La unión de los dos entes busca tener un accionar más amplio y eficaz para alcanzar las metas.

La Declaración de Rio -como comúnmente se le nombre- contiene 27 principios generales de aceptación internacional y está basado en la declaración de Estocolmo de 1972. Los principios generales de rio promueven un modelo peculiar para estructurar las normas ambientales, con las cuales se procura impulsar la fuerza de la protección en las leyes de los países (Organización de las Naciones Unidas, 1992, principio 11), ante la urgencia de implementar una guía internacional que marcara el camino hacia la protección ambiental, conteniendo elementos políticos, económicos y de derechos humanos se hacía cada vez más importante. Por esta razón este documento refuerza los principios de la Declaración de Estocolmo, ampliando el paradigma de protección del medio ambiente: 
Si bien la Declaración de Río en sí misma es un instrumento no vinculante, sus principios revisten gran importancia en la elaboración e implementación de la política y el derecho ambiental, tanto a nivel interno como a nivel internacional. Además, algunos de sus principios reflejan normas recogidas en el derecho consuetudinario internacional o en estándares establecidos en tratados internacionales (Orellan, 2014, P. 11).

Ella modificó el entendimiento del derecho internacional del medio ambiente, puesto que su elaboración atiende a una nueva demanda en las naciones diseñando el rumbo que debían tomar las decisiones políticas y económicas, que es la conservación de los recursos naturales, puesto que la actividad del hombre comienza a causar repercusiones irreversibles, como la degradación del agua provocada por la contaminación.

Tal como dice Püschel y Urrutia (2011, pp. 01 - 02) la declaración de rio refleja un consenso de las negociones entre los países más desarrollados de la época de 1992 para la protección ambiental, el paquete de 27 principios refresca el interés de operar con normas basadas en los derechos humanos y desarrollo sostenible. Demostrando que los estados se habían dado cuenta del rápido deterioro que se producía en el medio ambiente y el aumento de sus repercusiones.

Pese a los nuevos planteamientos ambientales y no los nuevos paradigmas por resolver, se acentúa que no se obtuvieron mejoras relevantes y ocurrió básicamente lo mismo que en la reunión de Johannesburgo en 2002. Estas reuniones seguían teniendo una intención de mejora, pero no tuvieron resultados efectivos.

La declaración de Johannesburgo o también conocida como Cumbre Mundial para el Desarrollo Sostenible, fue una reunión organizada en junio de 2002 en la cual se contó con una gran participación de altos mandos institucionales, jefes de Estado, líderes empresariales, representantes de organizaciones civiles y demás interesados en la materia ambiental (Organización de las Naciones Unidas, 2002, pp. 01 - 03).

La materia ambiental, al tener varios actores hace difícil poder llegar a una idea generalizada con principios generales aceptados por ellos. Muestra de esto es que para una gran parte de los 
asistentes, los resultados de Johannesburgo fueron insuficientes ante la incapacidad de arribar a acuerdos más benéficos mediante la negociación, de los retos que se presentaron y de los cuales habría que buscarse soluciones en común participación, nunca encontraron vía para su realización (La Vina, Hoff, y De rose, 2002, p. ii)

Con el ímpetu de brindar una mayor protección o poder implementar mecanismos efectivos para la protección del medio ambiente, provocan que las reuniones de los representantes de diversos Estados sean insuficientes, tal como ocurrió en la Cumbre Mundial para el Desarrollo Sostenible donde se retomaron aspectos ya tratados en anteriores reuniones. No obstante, se intentó brindar continuidad a los trabajos realizados esta vez aquellas buenas intenciones ambientalistas quedaron en letra muerta ya que no se llegaron a acuerdos tan sólidos y de impacto real para el medio ambiente (Eschenhagen, 2006 p. 54).

Los medios masivos de producción, así como el comercio global que desarrollado en las últimas décadas, cambiaron nuestra percepción del mundo y con ellas la modificación de nuestro entorno tanto social como ambiental. Ello motivó uno de los temas más debatidos en la Cumbre Mundial para el Desarrollo Sostenible que fue el hecho de que la globalización diera pie a que nuevas formas de producción se entrelazaran a otras variables como el flujo de dinero, mano de obra barata y principalmente a la baja regulación o muy flexible normatividad ambiental. Lo anterior condujo a que las grandes corporaciones aprovecharan esos factores e implementaran producciones a gran escala comercial con sacrificio ecológico (Eschenhagen, 2006, p. 56).La prioridad no era el medio ambiente, sino una economía fuerte sustentada en una percepción utilitarista del medio ambiente, adquiriendo valor en proporción a lo que pueda aportar a la economía.

Los problemas en la conferencia de Johannesburgo son la muestra de la complejidad que se tiene para llegar a acuerdos eficaces, como se mencionaba en líneas anteriores, puesto que no es suficiente la buena voluntad de los Estados. Dichos impedimentos fueron los siguientes:

1. Ausencia de acuerdos fuertes, operantes y factibles;

2. Ideas carentes de innovación para ayudar al medio ambiente; 
3. Nula colaboración entre gobiernos;

4. La globalización no fue atendida con la seriedad requerida;

5. Oportunidades políticas desperdiciadas (La Vina, Hoff, y De rose, 2002, pp. 02 - 04).

Por otro lado, en dicha conferencia destaco lo siguiente: El reconocimiento de la relevancia del sector empresarial y su rol en el medio ambiente;

1. La exhortación para la rendición de cuentas del sector empresarial;

2. La reafirmación el principio de acceso a la información;

3. Se incorporan principios éticos para el sector empresarial;

4. Se busca la desvinculación del crecimiento económico con la degradación ambiental (La vina, Hoff, y De rose, 2002 p. 07; Organización de las Naciones Unidas, 2002, párr. 48).

Varios de los motivos externos que influyeron en la declaración de Johannesburgo consistieron en que, simplemente se realizó en un periodo de alta tensión comercial y social, restando valor a lo estipulado en Estocolmo y Rio de Janeiro. Dicha inconsistencia se observa desde que el desarrollo sostenible toma mayor relevancia que el medio ambiente, no puede existir el primero sin el segundo o al menos se presume un equilibrio entre ambos.

Desde la declaración de Estocolmo hasta Johannesburgo, el Programa de Naciones Unidas para el Medio Ambiente -programa creado por la Organización de las Naciones Unidas -, se encarga de vigilar y evaluar a los diversos países y sus contextos con índices de desempeño en el medio ambiente, también presenta resultados y recomendaciones interesantes en sus diversos proyectos. En lo que atiende a México, según datos de la Universidad de Yale (2018, p. vii) se encuentra en la posición número 72 en el ranking mundial para el cuidado del medio ambiente y su protección del medio ambiente, mientras que regionalmente es el número 8 en toda Latinoamérica. Lo que demuestra las deficiencias dentro de la materia ambiental en nuestro país.

Posteriormente, en la ciudad de Rio de Janeiro en el año 2012, se efectuó nuevamente una de las reuniones mundiales más importantes del planeta. En ella se abordaron temas de impacto ecológico e intereses económicos. A esta reunión se le denomino Rio+20, que consiste en el 
recuento de los resultados y la visibilizarían de diversos escenarios por los cuales ha pasado la cumbre de la tierra.

La reagrupación de líderes de Estado, instituciones y demás grupos de interés fue encaminada a producir nuevos resultados y evitar caer en malos hábitos administrativos que han afectado al logro y metas de los objetivos del milenio; se señala la importancia de establecer y actualizar las bases para el desarrollo sostenible, puesto que los recursos día a día son más escasos y la población crece aumentando los índices de pobreza y hambruna es necesario actuar y pensar en nuestro futuro (Organización de las Naciones Unidas , 2012, pp. 10 - 13).

Una solución propuesta consiste en invertir en infraestructura de energías limpias, como parques eólicos, ciudades con paneles solares y especialmente en métodos de conservación y administración de los recursos hídricos para evitar la desertificación, para reducir el impacto ambiental generado por la producción de energías fósiles

Estos documentos desarrollan un aparato internacional diverso al interamericano, puesto que estos se inscriben en el sistema universal de derecho internacional, estableciendo las bases de un derecho autónomo al resto, mientras que el otro se sustenta en el sistema de derechos humanos, que se incorpora en nuestro sistema jurídico por medio del bloque de constitucionalidad. Por otro lado, los fundamentos del derecho internacional del medio ambiente surgen de estos, sirviendo de parámetro para su protección -entre ellos el derecho al agua-, por lo que sirven de marco para la actuación estatal.

Bajos estos supuestos, que integran el marco jurídico protector del derecho al agua así como su afectación al medio ambiente sano, por los cuales se desarrollan los principios del derecho al medio ambiente, a continuación, se analizará particularmente el caso del Rio Santiago en Jalisco, bajo las circunstancias que acaecen en las orillas de los municipios de El Salto y Juanacatlán, al ser una región donde no se protegió este derecho, mostrando las consecuencias ante su violación.

\section{Estudio de caso: omisión a la protección del derecho humano al agua}


El derecho al agua y su protección es motivo de un amplio debate ante las condiciones de facto y de derecho que influyen para la cualificación de su satisfacción. Un caso donde observamos las dificultades que enfrenta, visible en Jalisco ante las circunstancias en que se encuentra, es el Rio Santiago. Para comprender la trascendencia de este problema, es indispensable analizar el desarrollo de la actividad industrial en los municipios del El Salto y Juanacatlán en los cuales se encuentra uno de los corredores industriales más importantes de Jalisco sumado a su proximidad con el cuerpo de agua en cuestión causando un grave deterioro y causando un daño al medio ambiente.

Conforme a la información del directorio estadístico nacional de unidades económicas del Instituto Nacional de Estadística y Geografía, el municipio de El Salto cuenta con 6,772 unidades económicas a abril de 2019 y su distribución por sectores revela un predominio de unidades económicas dedicadas al comercio, siendo estas el $47.33 \%$ del total de las empresas en el municipio. Dentro de la región, El Salto ocupa la posición 6 de 12 en cuanto a la concentración de empresas y la posición 9 en el estado.

Asimismo, El Salto ha visto un crecimiento en el número de trabajadores registrados ante el Instituto Mexicano del Seguro Social, lo que se traduce en un incremento de sus grupos económicos. Para diciembre de 2018, el Instituto Mexicano del Seguro Social reportó un total de 51,528 trabajadores asegurados, lo que representa 16,183 trabajadores más que en diciembre de 2012 y 1,199 más que el año inmediato anterior.

En función de los registros del Instituto Mexicano del Seguro Social el grupo económico que más trabajadores tiene registrados dentro del municipio de El Salto, es el de Fabricación de productos metálicos, excepto maquinaria y equipo, que en 2018 registró un total de 7,986 trabajadores, concentrando el $15.50 \%$ del total de trabajadores asegurados en el municipio. Este grupo registró un aumento de 2,168 trabajadores con relación a 2012.

El segundo grupo económico con más trabajadores asegurados es la Construcción, reconstrucción y ensamble de equipo de transporte y sus partes, que para 2018 registró 5,605 
trabajadores asegurados que representan el $10.88 \%$ del total de trabajadores asegurados a dicha fecha. De 2012 a 2018 este grupo económico aumentó en 1,267 trabajadores.

Considerando el índice de medio ambiente, que contempla aspectos como generación de residuos sólidos, deforestación, explotación de acuíferos, cobertura forestal, aéreas naturales protegidas, entre otros, El Salto se ubica en el lugar 104 en este índice a nivel estatal, lo cual indica un desarrollo Muy Bajo del medio ambiente en comparación al resto de los municipios de la entidad, y la duodécima posición en la región Centro.

En el Índice Municipal de Medio Ambiente, 2013, destaca que El Salto se encuentra en un acuífero sin explotar, sobre el cual se registra un total de 32,214 viviendas particulares habitadas, de las cuales $82.24 \%$ tienen disponibilidad de agua dentro de la casa o el terreno y $96.92 \%$ cuentan con drenaje conectado a la red pública, fosa séptica u otros (Instituto de Información Estadística y Geográfica, 2019, 30).

Conforme a la información del directorio estadístico nacional de unidades económicas de Instituto Nacional de Estadística y Geografía, el municipio de Juanacatlán cuenta con 510 unidades económicas a noviembre de 2017 y su distribución por sectores revela un predominio de unidades económicas dedicadas a los servicios, siendo estas el $49.8 \%$ del total de las empresas en el municipio.

Por otro lado, el municipio de Juanacatlán ha visto diversas fluctuaciones en el número de trabajadores registrados ante el Instituto Mexicano del Seguro Social. Para diciembre de 2017, el IMSS reportó un total de 1,209 trabajadores asegurados, lo que representa 492 trabajadores más que en diciembre de 2013.

En función de los registros del Instituto Mexicano del Seguro Social el grupo económico que más trabajadores tiene registrados dentro del municipio de Juanacatlán, es el de fabricación y ensamble de maquinaria, equipos, aparatos y accesorios y artículos eléctricos, electrónicos y sus partes, que en el 2017 registró un total de 503 trabajadores concentrando el $41.6 \%$ del total de trabajadores asegurados en el municipio. Este grupo registró un aumento de 304 trabajadores en la comparación $2013-2017$. 
El segundo grupo económico con más trabajadores asegurados es el servicios profesionales y técnicos, que en el año 2017 registró 192 trabajadores asegurados que representan el 15.9\% del total de trabajadores asegurados a dicha fecha. De 2013 a 2017 este grupo tuvo un incremento de 100 trabajadores. Por otro, el índice municipal de medio ambiente, 2013, destaca que en Juanacatlán cuenta con un acuífero no sobrexplotado, sobre el cual se registra un total de 3,221 viviendas particulares habitadas, de las cuales $83.51 \%$ tienen disponibilidad de agua dentro de la casa o el terreno y $96.74 \%$ cuentan con drenaje conectado a la red pública, fosa séptica u otros.

El Municipio tiene una cobertura de $20.5 \%$ de bosques, $20.5 \%$ de selvas y $54.7 \%$ destinada a la agricultura. En los últimos 25 años el municipio ha recuperado $2.22 \mathrm{~km} 2$ de superficie con vegetación natural y presenta $7.27 \%$ de la superficie con riesgo de erosión. En el ordenamiento ecológico territorial, el $25.94 \%$ de su territorio está bajo políticas ambientales de conservación (Instituto de Información Estadística y Geográfica, 2018, p. 26).

En términos de residuos sólidos urbanos, el municipio participa con el $0.17 \%$ del total estatal, equivalente a 12.755 toneladas generadas por día (Instituto de Información Estadística y Geográfica, 2018, p. 28). Es por ello que Juanacatlán se ubica en el lugar 103 a nivel estatal del índice de medio ambiente, lo cual indica un desarrollo Bajo del medio ambiente en comparación al resto de los municipios de la entidad, y la segunda posición en la región Centro.

Ahora bien, podemos percatarnos de la dificultad para la satisfacción del derecho al agua a partir de las condiciones fácticas y jurídicas del presente caso, puesto que cerca de 100 mil habitantes de El Salto y Juanacatlán están en un medio ambiente de contaminación y deterioro evidente, donde las 370 industrias y pueblos circunvecinos descargan sus aguas residuales en el canal del Rio Santiago el cual actualmente está en el lugar 4 de los más contaminados en México (Enciso, 2004).

Esto se debe a que el corredor industrial que se encuentra de esta zona, empieza desde el sur de Tlaquepaque y recorre todo el municipio dando inicios a los daños ambientales, a ello se suman los canales que se interceptan por parte de la infraestructura de descarga de Guadalajara y Zapopan. Sin embargo, es en la zona de la presa del Ahogado donde la mayoría de las plantas 
industriales descargan sus desechos. Aunado a ello, solo el 50\% de las empresas tienen tecnología de tratamiento de desechos, y de ellos, solo el 50\% utiliza tal tecnología, lo cual aumenta el daño ambiental (Enciso, 2004, párr. 7).

Es por ello que, de acuerdo a González y la Secretaría del Medio Ambiente y Recursos Naturales (2010, párr. 3; 2016, pp. 58 - 59), el panorama general del rio Santiago de contaminación está fuertemente arraigado a la contaminación química y fecal. Desde el 2009, su mala calidad de agua ha incrementado; esto se debe a que 1500 empresas vierten sus residuos en las corrientes de agua del rio y sumado a ello la gran cantidad de aguas fecales hace que el rio concentre 1,000 número más probable de bacterias en $100 \mathrm{ml}$ de agua, sobrepasando los límites que permite la ley. Eventualmente el agua no puede consumirse por seres vivos ni ser utilizado para recreación u actividades productivas, por lo que el derecho de acceso al agua se encuentra disminuido en su satisfacción.

\section{Aplicación del sistema jurídico del medio ambiente al caso del Rio Santiago.}

Como se observó en la sección anterior los dos municipios analizados en este artículo son de una gran relevancia para comprender el problema respecto de la protección del derecho al agua y al medio ambiente. Por esta razón se desarrolló con especial énfasis el estudio, por considerar que es uno de los cuerpos acuáticos en México que más daños provoca en su población, así como en el ambiente.

Derivado de las circunstancias del Rio Santiago, estas propiciaron diversas medidas ante la constante transgresión al medio ambiente sano y el derecho al agua, que buscaron detener el deterioro ambiental y las vulneraciones a los derechos humanos. Por lo anterior, se emitieron diversas recomendaciones para solucionar las afectaciones que provocan al medio ambiente, y limitan el derecho al agua.

La primera en la que nos enfocaremos por su importancia, consiste en la Recomendación 009/2009, emitido por la Comisión Estatal de Derechos Humanos del Estado de Jalisco. Esta fue emitida como resultado de la excesiva contaminación que se puede encontrar en el Río Santiago, 
por una violación flagrante y evidente a los derechos humanos, donde la transgresión al derecho al agua, que a su vez vulneró al ambiente, causando un deterioro en el derecho a la salud, causando severas afectaciones a los habitantes de las regiones cercanas al río.

Ello fue causado por la polución, que es visible a simple vista por el color del agua, la excesiva espuma generada y los malos olores expedidos, afectando principalmente a los municipios de Juanacatlán y El Salto. Ello resulta en una evidente violación de los derechos consagrados en el artículo $4^{\circ}$ de la Constitución Política de los Estados Unidos Mexicanos (2021), que establece:

Artículo 4. [...]

$[\ldots]$.

Toda persona tiene derecho a la protección de la salud. La Ley definirá las bases y modalidades para el acceso a los servicios de salud y establecerá la concurrencia de la Federación y las entidades federativas en materia de salubridad general, conforme a lo que dispone la fracción XVI del artículo 73 de esta Constitución.

$[\ldots]$.

Toda persona tiene derecho a un medio ambiente sano para su desarrollo y bienestar. El Estado garantizará el respeto a este derecho. El daño y deterioro ambiental generará responsabilidad para quien lo provoque en términos de lo dispuesto por la ley.

$[\ldots]$

Toda persona tiene derecho al acceso, disposición y saneamiento de agua para consumo personal y doméstico en forma suficiente, salubre, aceptable y asequible. El Estado garantizará este derecho y la ley definirá las bases, apoyos y modalidades para el acceso y uso equitativo y sustentable de los recursos hídricos, estableciendo la participación de la Federación, las entidades federativas y los municipios, así como la participación de la ciudadanía para la consecución de dichos fines.

Por ello, la resolución se destaca la parte dirigida al Ejecutivo del Estado de Jalisco, en la que se le solicitó el cumplimiento de 100 puntos para revertir el impacto ambiental provocado; a los ayuntamientos de Guadalajara, Zapopan, Tlaquepaque, Tonalá, Tlajomulco de Zúñiga, El Salto, 
Juanacatlán, Ixtlahuacán de los Membrillos, Chapala, Poncitlán, Ocotlán, Tototlán, Atotonilco el Alto y Arandas, se les recomendó el cumplimiento de 68 puntos a cada uno para revertir el impacto e implementar medidas que permitan la satisfacción de estos derechos; a los organismos como la Comisión Estatal del Agua, se les recomendó cumplir con 13 puntos; y al Sistema Intermunicipal para los Servicios de Agua Potable y Alcantarillado, con 24 puntos. En lo referente a los municipios entorno del objeto de nuestra investigación- se hace relevante mencionar que se emitieron 68 recomendaciones para el municipio del Santo, los cuales aceptó en su totalidad, reportando un avance de 13 de ellos representando un $19.11 \%$ de avance. Por su parte Juanacatlán se encuentra en la misma situación con los mismos datos que su municipio vecino El Salto. (Comisión Estatal de Derechos Humanos Jalisco, 2009, pp. 237-265)

En estas recomendaciones podemos observar como la autoridad no jurisdiccional protectora de derechos humanos, concretiza los deberes enmarcados en el sistema jurídico nacional e internacional para brindar una solución a la constante violación del derecho humano al agua, al medio ambiente sano y a la salud, que se encuentran vinculados debido a que la violación de uno implica la transgresión de otros, debido al principio de indivisibilidad consagrado en el parámetro de constitucionalidad mexicano.

Una de esas medidas consiste en la gobernabilidad democrática para la gestión del agua. Mediante esta medida, se concretizaron los principios de protección del derecho ambiental y del agua, precisando la necesidad de incrementar y fortalecer los espacios de participación social efectivos, como implementar mecanismos claros para escuchar a los ciudadanos, y que su opinión sea considerada en la definición de políticas públicas desarrolladas para el mejor aprovechamiento del agua. Lo anterior se cumple al desarrollar lo siguiente:

1. Acceso a la información ambiental;

2. Acceso a la justicia ambiental;

3. Acceso a la participación pública;

4. Rendición de cuentas. 
Otra medida que concretiza el compromiso de fortalecer la democracia sustantiva, es la elaboración de convocatorias donde se invite a la sociedad civil y de la comunidad académica y científica, así como a especialistas para que analicen y determinen las acciones oportunas y convenientes para resolver los graves problemas de contaminación y sus efectos entre la población de las localidades establecidas en los márgenes de las cuencas de El Ahogado y del alto Santiago (El Salto, 2018, p. 4).

Con ello se desarrolla, a la par, otro principio del derecho ambiental que es la participación activa de la sociedad en la elaboración de políticas públicas para preservar el medio ambiente y el agua, como permitir la participación activa de las personas en la solución de problemas de esta materia, entendiendo que estos derechos imponen a los estados que colaboren con las personas por ser un derecho de interés difuso y colectivo.

Con la intención de encausar las actividades estatales frente a los actos en perjuicio del agua, se recomendó iniciar los procedimientos administrativos tendentes a la revocación de licencias, aquellos para cancelar los permisos de construcción y constancias de habitabilidad, que pretendan ubicarse en las márgenes del río Santiago, particularmente de escuelas y los giros para los cuales la contaminación represente un especial riesgo a la salud, y se abstengan de autorizar fraccionamientos y la instalación de empresas sin tener los estudios de impacto ambiental y sin prever que dichos giros o núcleos de población dejen de verter sus aguas sin tratar (El Salto, 2018, p. 5).

Bajo estas indicaciones se refuerza una característica de estos derechos sociales que consiste la participación activa del estado. Esto significa que ya no puede ser un participe ausente, donde la protección consiste en abstenerse de intervenir en las actividades de las personas, sino que tiene a su cargo el deber de realizar las acciones necesarias para crear condiciones que permitan la satisfacción de estos derechos. Por ello, se exhorto a ejercer las facultades para revocar aquellos actos que impliquen un riesgo para las personas ante la constante contaminación del Rio Santiago.

Ejemplo de estos deberes que implican una carga positiva para el estado, se recomendó a los municipios que deben considerar en sus leyes de ingresos, multas o sanciones a las industrias contaminantes y no depender únicamente de la Ley Federal de Derechos, que sólo prevé multas por 
incumplimiento de dos parámetros de calidad del agua (Demanda Química de Oxígeno y Sólidos Suspendidos Totales).

Así, mediante las medidas emitidas para actualizar el contenido de los tratados que conforman el marco jurídico para la protección del derecho al agua y medio ambiente, auxilian por un lado la actuación que se debe realizar por parte de las autoridades para el mayor cumplimiento de sus deberes sustantivos, y por otro, ante el problema que impera en el Rio Santiago, comenzar con medidas que permitan el resarcimiento del entorno, y reparar todo daño que se ocasionó al conjunto de derechos.

Sin embargo, estas medidas no sirvieron como modelo para direccionar la actuación de las autoridades, quienes fueron omisas en emprender acciones para reparar el daño ocasionado ante el incumplimiento de sus obligaciones, ejemplo de esto es que a pesar de que a el ejecutivo estatal se le pidió el cumplimiento de 100 puntos, solo se aceptaron 43, de los cuales solo se han reportado avances en un 37\%. También es importante mencionar que tanto El Salto y Juanacatlán cuentan con un avance del $19.11 \%$ esto a más de una década de ser emitida la recomendación. Derivado de ello, la Comisión Interamericana de Derechos Humanos emitió la resolución 07/2020 (2020), al agravarse la situación del rio.

Entre estas medidas se reitera de manera reducida aquellas emanadas por la Comisión Estatal de Derechos Humanos Jalisco, que consta de lo siguiente:

a) Adopte las medidas necesarias para preservar la vida, integridad personal y salud los pobladores de las zonas hasta 5 kilómetros del Río Santiago en los municipios de Juanacatlán y El Salto, así como los pobladores de las localidades de San Pedro Itzicán, Agua Caliente, Chalpicote y Mezcala en el municipio de Poncitlán, Estado de Jalisco, señalados en la solicitud. En particular, que el Estado adopte las medidas pertinentes para brindar un diagnóstico médico especializado para las personas beneficiarias, teniendo en cuenta la alegada contaminación, proporcionándoles asimismo una atención médica adecuada en condiciones de disponibilidad, accesibilidad, aceptabilidad y calidad, conforme a los estándares internacionales aplicables (Corte Interamericana de Derechos Humanos, 2020, p. 10). 
De esta medida se vuelven a concretizar los principios del derecho al medio ambiente y el derecho al agua, señalando las acciones que debe realizar el estado para lograr un nivel óptimo de protección de estos derechos. Además, dada la constante evolución de la contaminación del daño al Rio Santiago por la constante contaminación a su caudal, estas medidas tienden a reforzar el deber de reparación de los derechos violados ante las omisiones de implementar medidas para su adecuada satisfacción.

Sin embargo, podemos observar como aquellos documentos de difícil aplicación ante la generalidad de su contenido, fueron desarrollados tanto por la autoridad protectora local como la internacional. Jurídicamente, se demuestra que el desarrollo del contenido de dicho marco jurídico es posible, incluso al determinar las acciones que las autoridades deben realizar. No obstante, es el inicio de un proceso lejano de culminar, porque aún no se han materializado dichos principios por las autoridades que están obligadas a ello. Por lo que el tema debe estudiarse en su momento, a partir de lo que el estado realice para acatar dichas medidas donde cada ordenamiento se concretizó, o en su caso, la condena que reciba ante la constante omisión de emprender acciones para respetar y reparar el derecho al medio ambiente sano y al agua.

\section{La necesidad de implementar un sistema de justicia ambiental.}

A pesar de la existencia de un organismo no jurisdiccional para la protección del derechos al agua y medio ambiente como derechos humanos y de un sistema internacional de justicia de derechos humanos, ambos mecanismos no son plenos para proteger el derecho al agua, en virtud de que el primero no tiene facultades coercitivas para hacer exigibles sus determinaciones, y el segundo lo analiza desde la perspectiva de derechos humanos, implicando que las acciones que contaminan se perpetúen mientras no representen una afectación a los derechos humanos. 
Derivado del problema ocasionado al Rio Santiago, es menester instaurar un sistema de justicia ambiental a cargo del Poder Judicial del Estado de Jalisco. Dicha pretensión tiene dos sustentos: uno de carácter teórico y otro de carácter legal.

El primero de ellos atiende a la teoría del garantismo, puesto que esta propone que el desarrollo del derecho necesita de una instancia jurisdiccional para la protección de los derechos, y con ello su plena realización. Ferrajoli (2010), precisa que son obligaciones que asumen los estados de implementar los mecanismos necesarios para sancionar actos ilícitos o actos no validos que violen derechos subjetivos (p. 64). Una de las propuestas consiste en que cualquier contenido de derecho es incompleto cuando no existe la instancia ante la cual puedan reclamarse una violación, y la otra, que el Estado -Jalisco no se exime de dicha responsabilidad- debe desarrollar como sujeto constreñido para promover, respeto, proteger y garantizar los derechos.

Reforzando la postulación teórica, el 25 de junio de 1998 fue celebrado el Convenio de Aarhus, donde fue señalado en el concierto internacional el deber de garantizar el acceso a la justicia en materia ambiental. En su artículo $1^{\circ}$ señala como objetivo la obligación de garantizar el acceso a la justicia ambiental. La intención de reforzar dicha obligación consiste en reforzar los principios decretados en la Declaración de Estocolmo, la Declaración de Rio sobre el Medio Ambiente y el Desarrollo, y el resto de los tratados internacionales buscando que su contenido y las leyes emanadas de la recepción de ellos en los países, se materialicen ante el creciente deterioro al agua.

El Estado de Jalisco carece de una estructura que permita el ejercicio de la justicia ambiental, limitándose al conocimiento de esta materia mediante la emisión de actos administrativos cuando las empresas ameritan una multa por violar el contenido del marco jurídico ambiental. Con base en el artículo 9.1. de la Convención de Aarhus (1998), para cumplir con el acceso a la justicia ambienta, debe realizarse lo siguiente:

Artículo 9. Acceso a la justicia

1. Cada Parte velará, en el marco de su legislación nacional, porque toda persona que estime que su solicitud de información en aplicación del artículo 4 no ha sido atendida, ha sido 
rechazada ilícitamente, en todo o en parte, no ha obtenido una respuesta suficiente, o que, por lo demás, la misma no ha recibido el tratamiento previsto en las disposiciones de dicho artículo, tenga la posibilidad de presentar un recurso ante un órgano judicial o ante otro órgano independiente e imparcial establecido por la ley.

En el caso de que una Parte establezca tal recurso ante un órgano judicial, velará porque la persona interesada tenga también acceso a un procedimiento rápido establecido por la ley que sea gratuito o poco oneroso, con miras al reexamen de la solicitud por una autoridad pública o a su examen por un órgano independiente e imparcial distinto de un órgano judicial.

Las decisiones finales adoptadas en virtud del presente apartado 1 serán obligatorias para la autoridad pública que posea las informaciones. Los motivos que las justifiquen se indicarán por escrito, por lo menos cuando se deniegue el acceso a la información en virtud de este apartado.

Las determinaciones del Poder Judicial no son determinantes para la protección y reparación del impacto al agua. Una de las razones consiste en la naturaleza de la Comisión Estatal de Derechos Humanos Jalisco, cuyas recomendaciones no son vinculantes, otorgando la facultad a la autoridad responsable de aceptarla o no, se de manera parcial o total. A la par, las resoluciones que emanan del Tribunal de Justicia Administrativa derivado de un acto administrativo, solo juzgan su legalidad, pero carecen de una facultad para ordenar una acción concreta para reparar el daño ocasionado, o sancionar al infractor de la norma.

Por lo tanto, justicia ambiental debe recaer en un organismo judicial que pueda exigir el cumplimiento de sus determinaciones de manera coercitiva, para la realización del marco jurídico ambiental diseñado con las leyes mexicanas para su protección y los tratados internaciones que se incorporan por tutelas un derecho humano, eliminando la discrecionalidad de cumplimiento que actualmente existe.

Para ello, es necesario ampliar las facultades del Poder Judicial del Estado de Jalisco. La competencia originaria para conocer de las controversias en las distintas materias de derecho, recae 
en el Supremo Tribunal del Estado de Jalisco (Constitución Política del Estado Libre y Soberano de Jalisco, 2020, art. 62 fr. I). Bajo el principio de sujeción a la ley, todas las autoridades solamente pueden realizar aquello que les es permitido. Por lo que el Poder Judicial representado por el Supremo Tribunal de Justicia del Estado de Jalisco, solamente conoce de las controversias del orden penal, civil, de lo familiar y mercantil. El primer cambio consiste en la inclusión de las controversias en materia ambiental para darle potestad para emitir deliberaciones sobre la materia.

El siguiente cambio consistiría en la modificación a la Ley Orgánica del Poder Judicial del Estado de Jalisco (2020). Mediante esta se podrá elaborar la estructura orgánica con la que el Poder Judicial delimite las competencias de cada órgano a fin de garantizar el acceso a la justicia ambiental pronta y expedita.

El primero de ellos es el artículo 23 de la Ley Orgánica del Poder Judicial del Estado de Jalisco (2020). Este artículo determina las facultades del Pleno del Supremo Tribunal del Estado de Jalisco que, de manera similar, comprenden aquellas señaladas en el artículo 56 fracción I de la Constitución Política Del Estado de Jalisco. Para darle la capacidad de regular la función en el interior del tribunal, debe ampliarse su facultad y que conozca de esta materia.

Posteriormente, es menester la elaboración de un artículo 49 Bis en la ley, con la que se establezca una sala que conozca de los asuntos ambientales. Recordando que nuestro sistema jurídico es garantista, debe establecerse una instancia que se encargue de la revisión de las resoluciones de la autoridad judicial que emitan. Con ello, se pretende proteger el principio de legalidad que rige todo acto, para que las resoluciones no transgredan el marco jurídico.

Por último, es indispensable incorporar la fracción VI al artículo 101 de la Ley Orgánica del Poder Judicial del Estado de Jalisco (2020). Este artículo delimita la competencia de cada juzgado que conforma el Poder Judicial del Estado de Jalisco. Con ello se impone el deber de implementar juzgados en materia ambiental que representan el acceso a la justicia ambiental. Ante ellos se ejercerán derechos y excepciones; se desahogarán pruebas; se formularán alegatos para dictar una sentencia, donde cada parte pueda ser llamado a juicio, desarrollando los principios de la Convención de Aarhus. 
Con ello, la justicia ambiental podrá ser instaurada, en armonía con los principios de la tutela judicial efectiva, garantizando el derecho de recurrir los fallos en una instancia superior (Constitución Política de los Estados Unidos Mexicanos, 2021, art. 17). El contenido de la convención, con el contenido de nuestra carta magna permitirían el desarrollo óptimo de un mecanismo con el que se proteja de manera eficaz el derecho al agua y los alcances que este posee con el derecho al medio ambiente y se sancione a quien transgreda el marco jurídico que lo protege.

\section{Conclusiones}

Los esfuerzos para proteger el derecho al agua y el saneamiento, así como su relación con un medio ambiente sano en el Estado de Jalisco son insuficientes, por no poder promover, respetar, proteger y garantizarlo, tal como se desprende del caso del Rio Santiago, así como a las personas que fueron afectadas por el contacto con ello. Esto se debe a la primacía de las actividades económicas ocasionado por el fomento al desarrollo económico, propiciando que las autoridades obligadas a presérvalo emitieran una serie de recomendaciones de carácter no vinculante. Por ello, debe emprenderse las acciones necesarias para implementar un sistema de justicia ambiental, que permita el desarrollo y protección del derecho humano al agua y el saneamiento, así como a la reparación y coerción de cualquier violación a él, desarrollando los principios del derecho internacional del medio ambiente en nuestro Estado, que se asumió garantista en el nuevo paradigma del derecho contemporáneo.

\section{Referencias}

Cámara de Diputados. (2018). Ley General del Equilibrio Ecológico y la Protección al Ambiente. Recuperado de: http://www.diputados.gob.mx/LeyesBiblio/pdf/148_180121.pdf

Cámara de Diputados. (2020). Ley de Aguas Nacionales. Recuperado de: http://www.diputados.gob.mx/LeyesBiblio/pdf/16_060120.pdf 
Cámara de Diputados. (2021). Constitución Política de los Estados Unidos Mexicanos. Recuperado de: http://www.diputados.gob.mx/LeyesBiblio/pdf/1_110321.pdf

Comisión Estatal de Derechos Humanos del Estado de Jalisco. Recomendación 001/2009. Recuperado de: http://cedhj.org.mx/recomendaciones/emitidas/2009/rec0901.pdf

Comisión Interamericana de Derechos Humanos. (2020). Resolución 07/2020. Recuperado de: https://www.oas.org/es/cidh/prensa/comunicados/2020/MC70819.pdf

Congreso del Estado de Jalisco. (2020). Constitución Política del Estado Libre y Soberano de Jalisco.

Recuperado de:

https://congresoweb.congresojal.gob.mx/BibliotecaVirtual/busquedasleyes/Listado.cfm\#Co digos

Congreso del Estado de Jalisco. (2020). Ley Orgánica del Poder Judicial del Estado de Jalisco. Recuperado de: https://congresoweb.congresojal.gob.mx/BibliotecaVirtual/busquedasleyes/Listado.cfm\#Ley es

Enciso, A. (2004). Impune contaminación cubre a El Salto, Jalisco. La Jornada. Jalisco, México.

Eschenhagen, M. (2006). Las cumbres ambientales internacionales y la educación ambiental. Oasis 2006-07, núm. 12, Centro de Investigaciones y Proyectos Especiales. Colombia. Pp. 39-76.

Ferrajoli, L. (2010). Democracia y derecho. España: Trotta.

González, M. (2010). Realizan censos de empresas en El Salto. Universidad de Guadalajara. México. Instituto de Información Estadística y Geográfica de Jalisco. (2019). Juanacatlán: Diagnóstico municipal mayo 2018. Recuperado de: https://iieg.gob.mx/contenido/Municipios/Juanacatlan.pdf

Instituto de Información Estadística y Geográfica de Jalisco. (2019). El Salto: Diagnóstico municipal marzo 2019. Recuperado de: https://iieg.gob.mx/ns/wp-content/uploads/2019/06/ElSalto.pdf 
El Salto. (2018). Minuta de la segunda sesión ordinaria de la comisión edilicia de los Derechos $\begin{array}{lll}\text { Humanos. } & \text { Recuperado de https://elsalto.gob.mx/portal- }\end{array}$ api/public/transparencia/docs/1563295834166.docx

La Vina, A., Hoff, G. y De rose, A. (2002). Éxitos y fracasos de Johannesburgo: una historia de muchas cumbres. World Resources Institute. s, I.

Marcos A. Orellana (2014) Tipologia de instrumentos de derecho público ambiental internacional. Publicación de las Naciones Unidas

Organización de los Estados Americanos. (1969). Convención Americana de Derechos Humanos. Recuperado de: https://www.oas.org/dil/esp/tratados_b32_convencion_americana_sobre_derechos_humanos.htm

Organización de los Estados Americanos. (1999). Protocolo Adicional a la Convención Americana sobre Derechos Humanos en Materia de Derechos Económicos, Sociales y Culturales "Protocolo de San Salvador". Recuperado de: https://www.oas.org/juridico/spanish/tratados/a-52.html

Organización de las Naciones Unidas. (1972). Declaración de Estocolmo sobre el medio ambiente humano. Recuperado de: http://www.upv.es/contenidos/CAMUNISO/info/U0579218.pdf

Organización de las Naciones Unidas. (2002). Declaración de Johannesburgo sobre el Desarrollo Sostenible. Recuperado de: http://appweb.cndh.org.mx/derechoagua/archivos/contenido/CPEUM/E4.pdf

Organización de las Naciones Unidas. (1992). Declaración de rio sobre el medio ambiente y el desarrollo.

Recuperado de: https://www.un.org/spanish/esa/sustdev/agenda21/riodeclaration.htm

Organización de las Naciones Unidas. (1998). Convenio de Aarhus sobre acceso a la información, participación del público en la toma de decisiones y acceso a la justicia en materia de medio ambiente. Recuperado de: https://www.oas.org/es/sla/ddi/docs/acceso_informacion_desarrollos_convenio_aahrus.pd $f$ 
Organización de las Naciones Unidas. (2012). Rio+20: Conferencia de las naciones unidas sobre el desarrollo sostenible. Recuperado de: https://www.un.org/sustainabledevelopment/es/development-agenda/

Püschel, L. y Urrutia, O. (2011). Principios del Derecho Internacional Ambiental. Pontificia Universidad Católica de Valparaíso. Chile.

Secretaria del Medio Ambiente y Recursos Naturales. (2016). Programa de manejo integral de la cuenca del rio Santiago-Guadalajara. Universidad Nacional Autónoma de México, campus Michoacán. Michoacán, México.

Yale University. (2018). Environmental performance index. Yale Center for Environmental Law \& Policy. United States of America. 